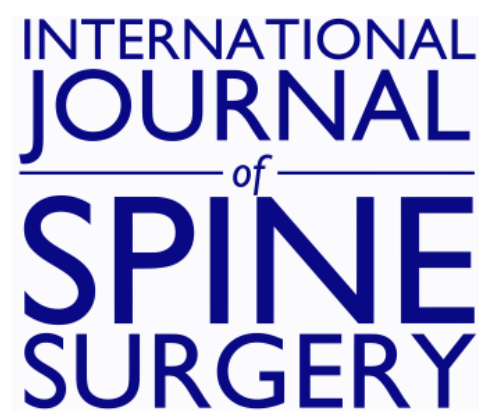

\title{
Early Recurrent Symptoms After Anterior Cervical Discectomy and Fusion Done for Myelopathy
}

Andrew MacCormick and Himanshu Sharma

Int J Spine Surg 2021, 14 (s4) S1-S4

doi: https://doi.org/10.14444/7171

http://ijssurgery.com/content/14/s4/S1

This information is current as of April 26, 2023.

Email Alerts Receive free email-alerts when new articles cite this article. Sign up at:

http://ijssurgery.com/alerts

The International Journal of Spine Surgery

2397 Waterbury Circle, Suite 1,

Aurora, IL 60504, Phone: +1-630-375-1432 


\title{
Early Recurrent Symptoms After Anterior Cervical Discectomy and Fusion Done for Myelopathy
}

\author{
ANDREW MACCORMICK, BMBS \\ Radiology Registrar, University Hospitals Plymouth NHS Trust, Plymouth PL6 8DH \\ HIMANSHU SHARMA, BSC, MB BS, MS, MCH, FRCS ED, FRCS \\ Consultant Spine Surgeon, South West Neurosurgery Centre, Derriford Hospital, Plymouth PL6 8DH
}

\begin{abstract}
We present a unique case with early recurrent myelopathic clinical manifestations following anterior cervical discectomy and fusion; however, he had an eventual diagnosis of multiple sclerosis rather than any residual cord compression on repeat imaging.
\end{abstract}

Cervical Spine

\section{INTRODUCTION}

Cervical spondylosis and other related disorders are increasing in prevalence in Western society. ${ }^{1}$ Since Smith and Robinson ${ }^{2}$ first introduced anterior cervical discectomy and fusion (ACDF) in the 1950s, an increasing number of operations have been performed in the United Kingdom each year. ${ }^{3}$ As a result, ACDF has long been regarded as the gold standard for the management of single or multilevel cervical vertebral disease associated with compressive myelo-radiculopathy. ${ }^{4}$ Many of the clinical manifestations of cervical myelopathy may also mimic other neurological disorders and due to this, it remains undiagnosed or underdiagnosed ${ }^{5}$ in the general population and is often only diagnosed when the disease has significantly progressed clinically or radiologically.

We present a unique case with clinical manifestations and magnetic resonance imaging (MRI) findings of compressive cervical myelopathy and underwent ACDF; however, he had an eventual diagnosis of multiple sclerosis with recurrent symptoms postoperatively.

\section{CASE REPORT}

A 41-year-old male, otherwise fit and healthy, presented to clinic after his musical colleagues noted that his guitar playing ability had reduced over the past 9 months. As a music teacher, the patient was regularly playing the guitar with the neck in a hyperextended position. This fine motor skill decline then progressed to numbness affecting the hands and feet bilaterally and he developed persistent tiredness and weakness affecting all 4 limbs. He had no history of poor balance, unsteadiness, or dropping objects; however, he had reduced exercise tolerance as he developed paresthesia of the legs while cycling. Initial examination showed a full range of movement in his neck and shoulders. Romberg test was weakly positive, and Hoffman test was positive, mainly on the left side. All reflexes (knee, biceps, and triceps) were brisk. Examination of the cranial nerves was unremarkable. An initial MRI scan showed a central posterior disc bulge at the $\mathrm{C} 3 / \mathrm{C} 4$ level with the disc partially indenting the cord and a large posterior disc osteophyte complex at the $\mathrm{C} 4 / \mathrm{C} 5$ level, which was compressing the cord (Figures 1-4). There was associated intrinsic signaling consistent with cervical myelopathy. Cerebrospinal fluid effacement and cord signals were demonstrated with myelomalacia. A subsequent diagnosis of $\mathrm{C} 3 / \mathrm{C} 4$ and $\mathrm{C} 4 / \mathrm{C} 5$ severe cervical canal stenosis with spinal compressive myelopathy was made.

The patient underwent a $\mathrm{C} 3 / \mathrm{C} 4$ and $\mathrm{C} 4 / \mathrm{C} 5$ $\mathrm{ACDF}$, and there were no intraoperative or early postoperative complications. The patient reported an improvement in his symptoms postoperatively.

However, 5 weeks postoperatively, the patient reported recurrence of tingling, numbness, and burning in his hands and feet that came on 


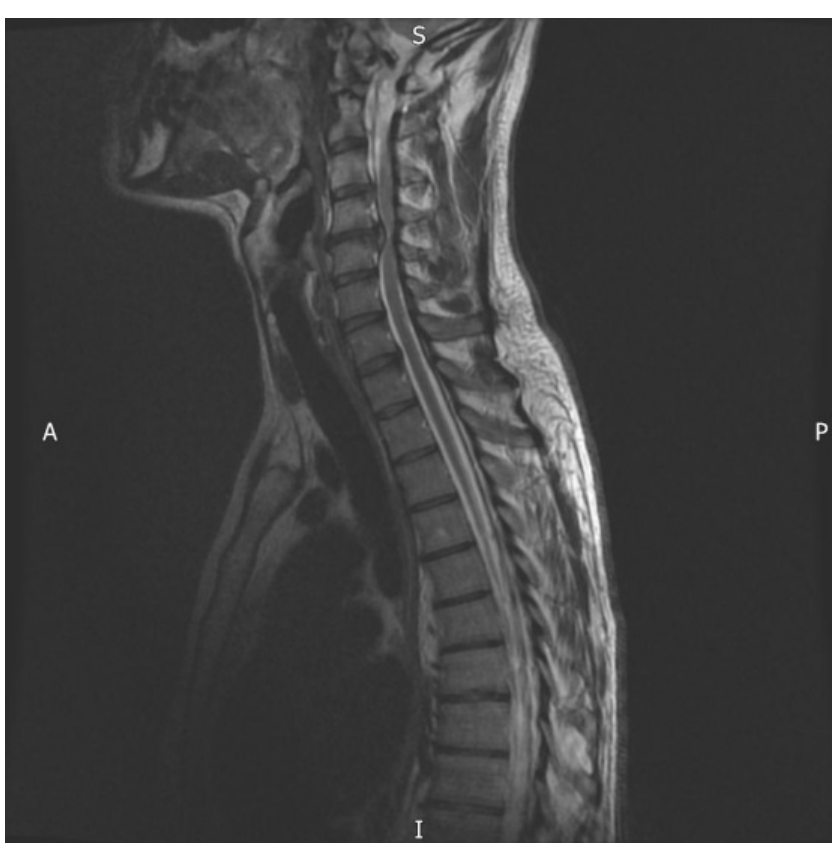

Figure 1. Pre-operative MRI scan (sagittal).

suddenly. This was associated with weakness of the legs and aching of the neck, described as intermittent and moderate to severe. All reflexes remained brisk on examination with the cranial nerves unremarkable.

A repeat MRI scan confirmed no residual compression of the spinal cord and no postoperative complications (Figures 5 and 6). As well as this, $x-$ rays of the cervical spine confirmed satisfactory process of fusion and satisfactory positioning of the

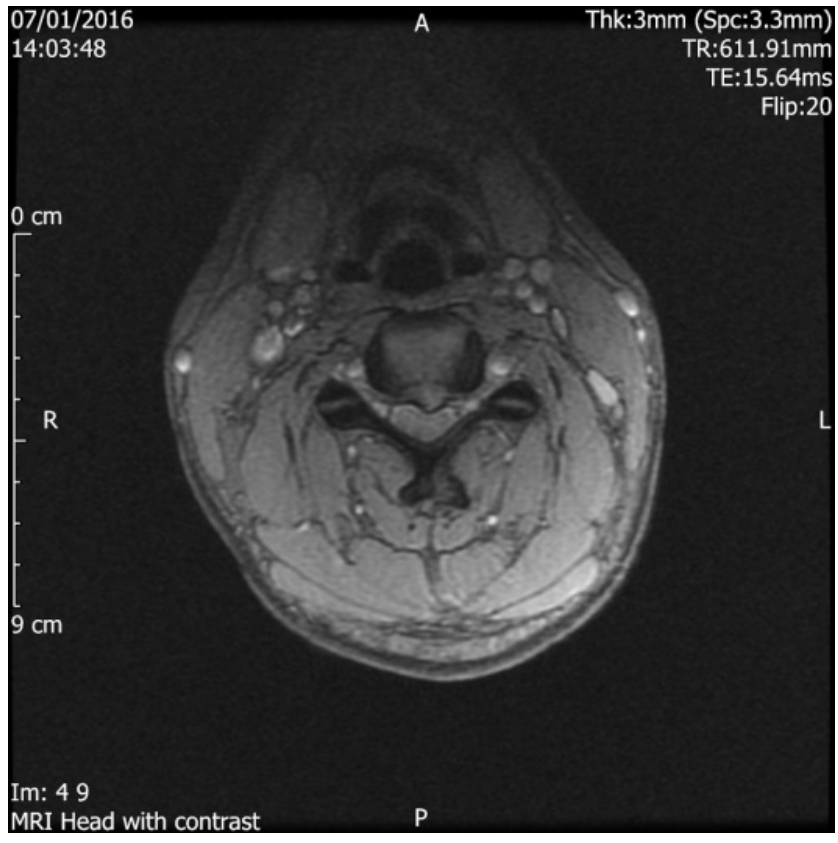

Figure 2. Pre-operative MRI scan (axial).

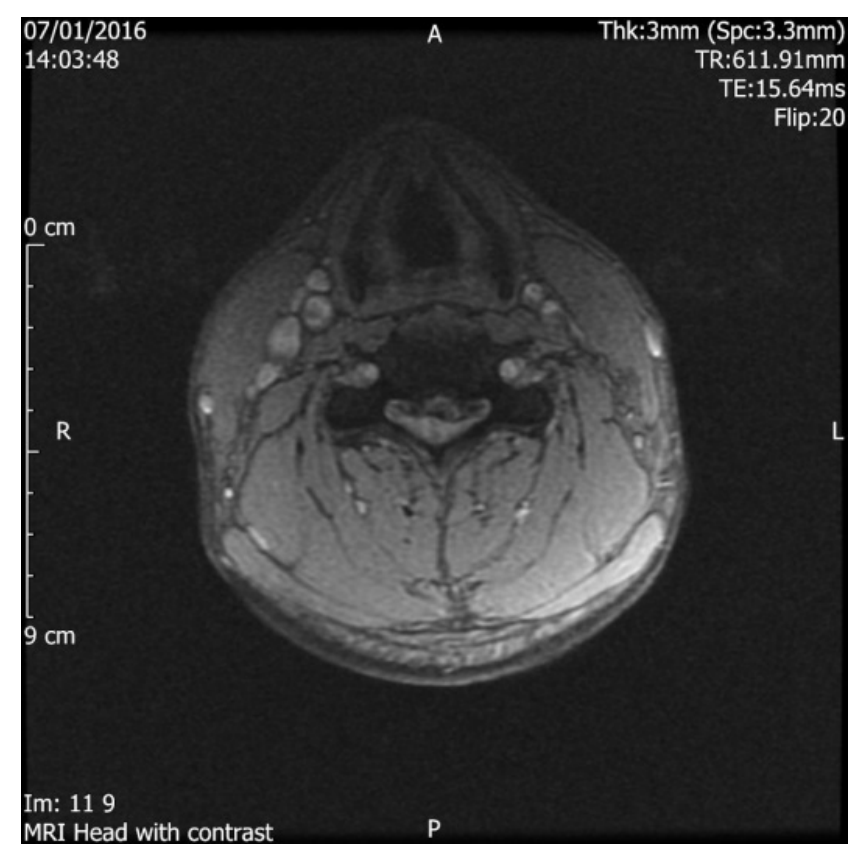

Figure 3. Pre-operative MRI scan (axial).

cages in the intervertebral spaces. He was closely observed.

The patient was then admitted to hospital 1 month later under neurology team with worsening symptoms in the arms and the legs. This time, however, an MRI scan confirmed evidence of transverse myelitis (Figure 7), and the patient was placed on intravenous high dose steroid therapy for 3 days. A lumbar puncture demonstrated the presence of oligo-clonal bands and following

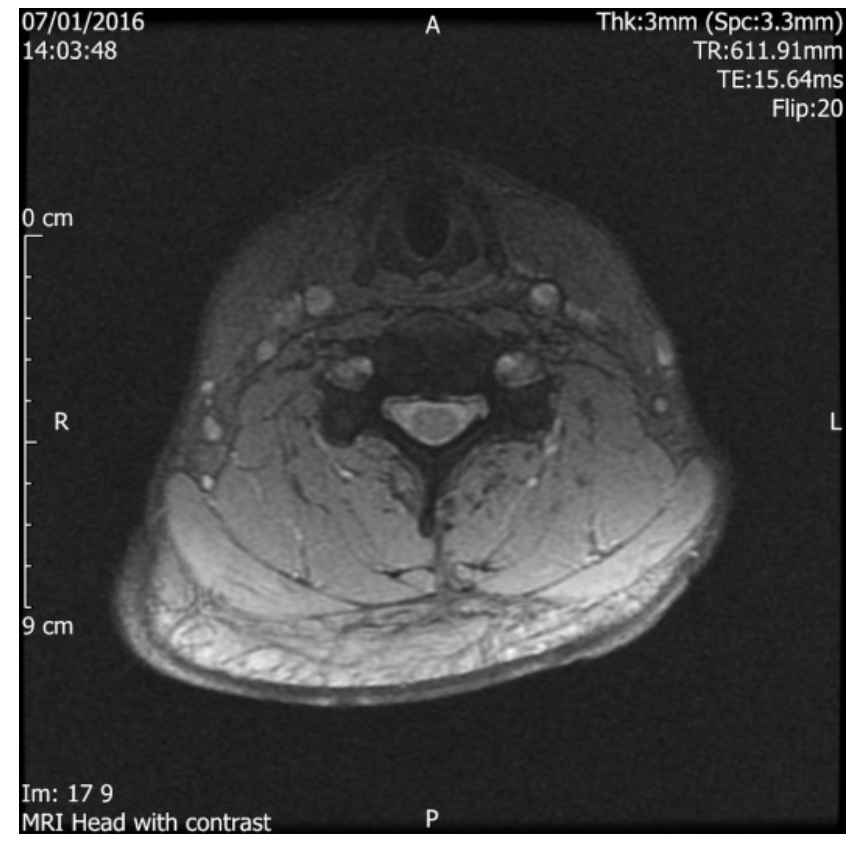

Figure 4. Pre-operative MRI scan (axial). 


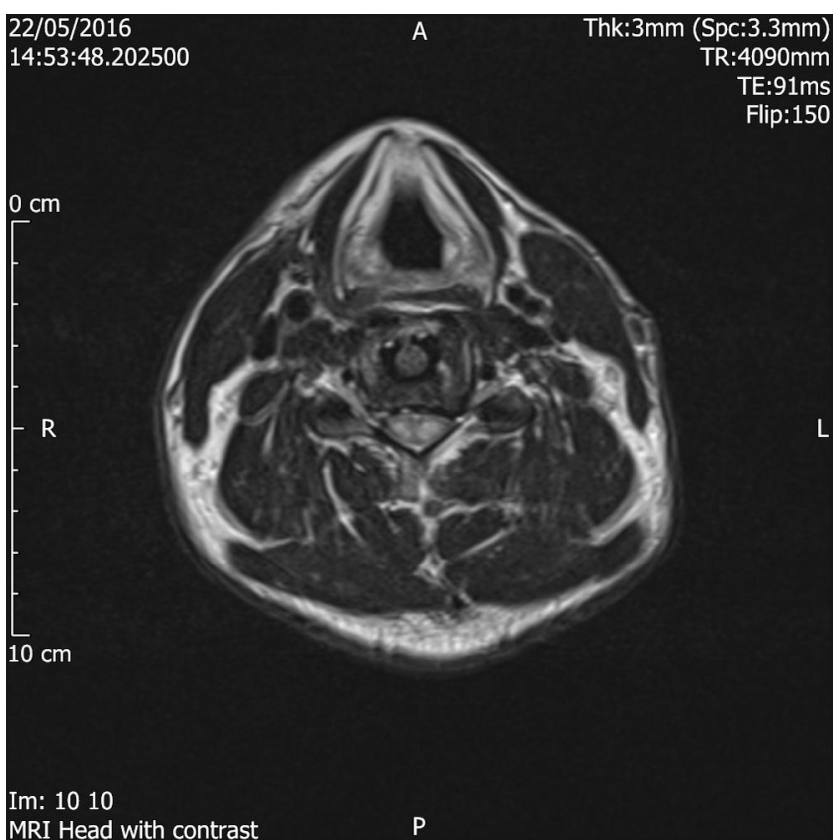

Figure 5. Post-operative MRI scan (axial).

specialist referral, a diagnosis of spinal multiple sclerosis was made using the generic Poser criteria.

\section{DISCUSSION}

Following a literature review, we identified no other similar cases so this appears to be a unique sequence of presentation. However, studies have described the incidence and outcomes of ACDF in patients with preexisting multiple sclerosis who have

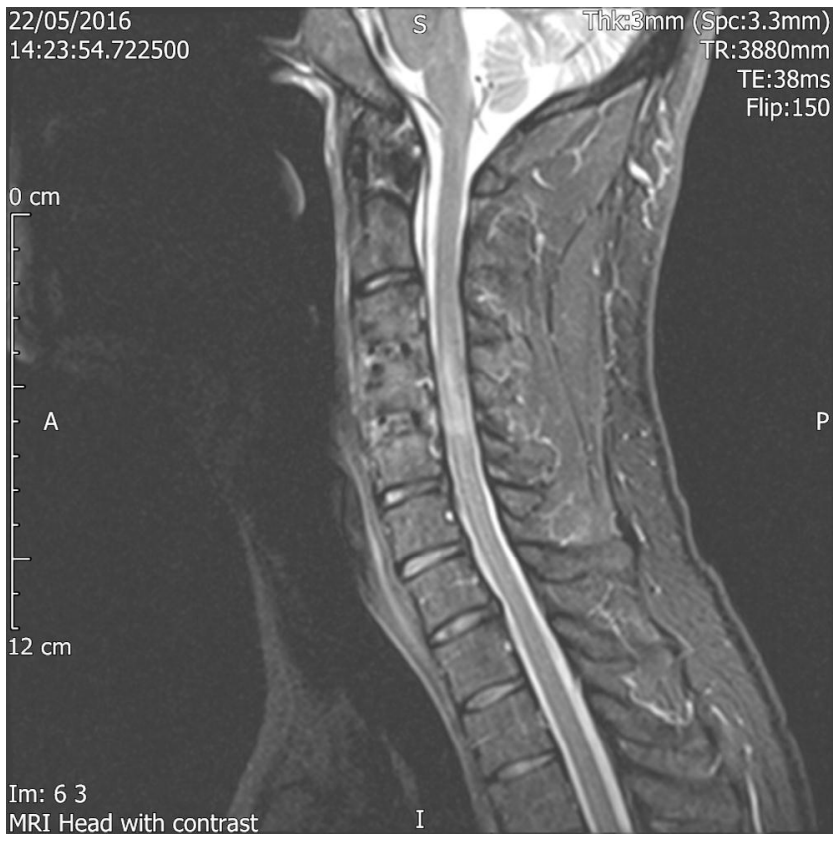

Figure 6. Post-operative MRI scan (sagittal).

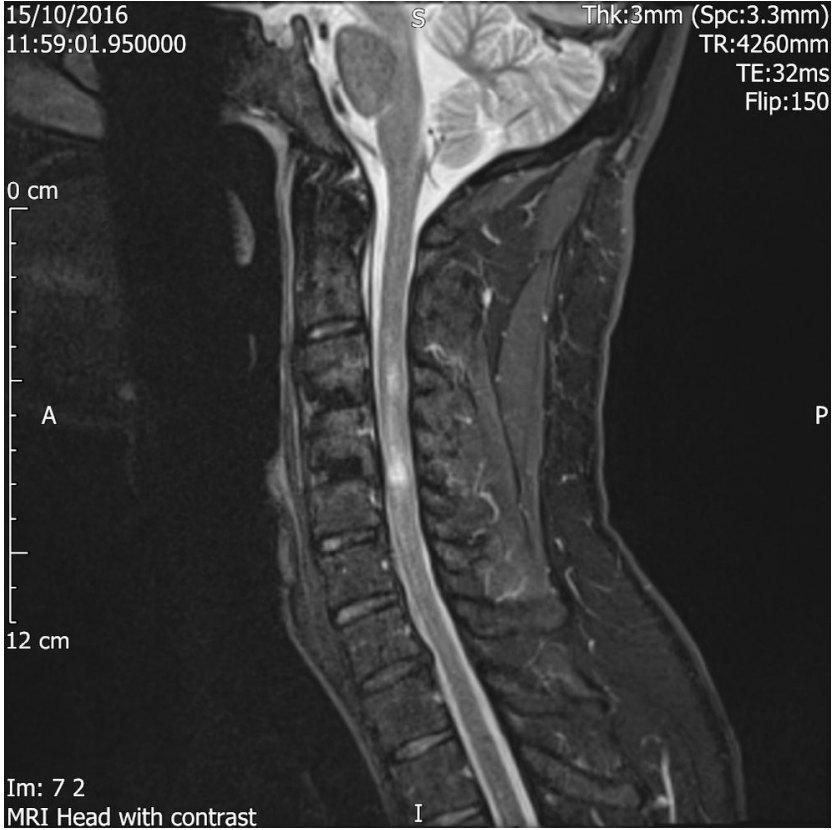

Figure 7. MRI scan performed when re-admitted under the care of the Neurology team (sagittal).

developed cervical myelopathy. ${ }^{6}$ This case presented a diagnostic dilemma for recurrence of myelopathic manifestations within the early postoperative period. This could be residual cord compression, compression at neighboring level(s), or occurrence of a new neurological condition. As a patient and as a surgeon, early recurrent symptoms pose undue anxieties. This patient had the ACDF performed at an early period within the usual clinical timeline of cervical myelopathy because, due to his job role as a music teacher, he was able to notice the decline in his fine motor function early. It is more common for individuals to present later with more severe symptoms. In the immediate postoperative period, it appeared that this patient had a good outcome as he experienced a significant improvement in his symptoms initially.

Within this early postoperative period, if there is a recurrence of myelopathic symptoms, the main differentials can be divided to extrinsic factors leading to cord compression or intrinsic cord factors. Extrinsic cord factors would include incomplete surgical decompression, cage loosening or displacement, and low grade infection with epidural collection. There is also the possibility that compression at another level that was not operated on could be the cause as often radiological findings do not correlate with clinical findings. Repeat x-rays, computed tomography scan, and MRI imaging should be considered to exclude these possibilities 
as revision operation may be required in patients with residual compression.

Intrinsic cord factors would include neurological disorders such as multiple sclerosis, which was seen in this case or could include a syrinx within the spinal cord. In this case, the patient had multiple sclerosis, which appeared to be dormant prior to the operation and then the patient had a significant improvement in his symptoms in the immediate postoperative period. This raises the question whether the operative stress or anesthetic process triggered off multiple sclerosis, a phenomenon that has been highlighted in recent literature. ${ }^{7}$ Because he had compressive myelopathy, cervical spinal surgery could be justified. Upon review of the initial postoperative MRI scan, there is evidence of edema that was felt to represent postsurgical change. This may have been, with the balance of retrospective, earlier multiple sclerosis findings, so this highlights the importance of this diagnosis being considered in the future.

If a patient has an early recurrence of myelopathic symptoms following an ACDF procedure, we feel that the differentials discussed can be of use for the operating surgeon to consider. It is of paramount importance that once extrinsic factors have been excluded by repeat x-rays and MRI imaging, surgeons should consider intrinsic cord pathologies such as multiple sclerosis, so timely neurology referral is expedited.

\section{REFERENCES}

1. Roh JS, Teng AL, Yoo JU, Davis J, Furey C, Bohlman HH. Degenerative disorders of the lumbar and cervical spine. Orthop Clin North Am. 2005;36(3):255-262. doi:10.1016/j.ocl. 2005.01.007
2. Smith GW, Robinson RA. The treatment of certain cervical-spine disorders by anterior removal of the intervertebral disc and interbody fusion. J Bone Joint Surg Am. 1958;40A(3):607-624.

3. Fountas KN, Kapsalaki EZ, Nikolakakos LG, et al. Anterior cervical discectomy and fusion associated complications. Spine. 2007;32(21):2310-2317. doi:10.1097/BRS.0b013e318154c57e

4. Chen F, He W, Mahaney K, et al. Alternative grafts in anterior cervical fusion. Clin Neurol Neurosurg. 2013;115(10):20492055. doi:10.1016/j.clineuro.2013.07.013

5. Guan L, Hai Y, Yang J-C, Zhou L-J, Chen X-L. Anterior cervical discectomy and fusion may be more effective than anterior cervical corpectomy and fusion for the treatment of cervical spondylotic myelopathy. BMC Musculoskelet Disord. 2015;16:29. doi:10.1186/s12891-015-0490-9

6. Purvis TE, Lubelski D, Mroz TE. Is decompressive surgery for cervical spondylotic myelopathy effective in patients suffering from concomitant multiple sclerosis or Parkinson's disease? Brain Sci. 2017;7(4):39. doi:10.3390/brainsci7040039

7. Acar A, Nuri Deniz M, Erhan E, Ugur G. Anesthetic technique in a patient with multiple sclerosis scheduled for laparoscopic nephrectomy for a renal tumor: a case report. Anesth Pain Med. 2013;2(3):138-140.

Disclosures and COI: The authors received no funding for this study and report no conflicts of interest.

Corresponding Author: Andrew P. MacCormick, BMBS, South West Neurosurgery Centre, Derriford Hospital, Plymouth PL6 8DH, United Kingdom. Phone: (+44) 774-245-4630; Email: andrew.maccormick@nhs.net.

Published 11 February 2021

This manuscript is generously published free of charge by ISASS, the International Society for the Advancement of Spine Surgery. Copyright (C) 2020 ISASS. To see more or order reprints or permissions, see http://ijssurgery.com. 